\title{
COMICIDAD, EMBLEMÁTICA \\ Y EL CHISTE DE LA ESPORTILLA \\ EN LA CASA HOLGONA DE CALDERÓN
}

\author{
Pablo Restrepo-Gautier \\ Hispanic and Italian Studies \\ Faculty of Humanities \\ University of Victoria \\ P. O. Box 1700 STN CSC \\ Victoria. Canada \\ restrepo@uvic.ca
}

[Anuario calderoniano (ISSN: 1888-8046), 7, 2014, pp. 215-228]

Cuando una de las prostitutas del entremés de La casa holgona [1643] de Calderón ${ }^{1}$ se queja con falsedad, diciéndole a Antón que «El

${ }^{1}$ Es necesario advertir aquí que la autoría de Calderón de La casa holgona no se ha demostrado, como lo señala Lobato en su edición del entremés (Calderón, La casa holgona, 1989, p. 94). Sin embargo, hay indicios de que quizá sí lo sea y, por lo tanto, se incluye en ediciones del teatro breve calderoniano, como la de Lobato y la de Rodríguez Cuadros y Tordera. 
corazón me deja lastimado, / el bazo herido, el hígado llagado»², el capigorrón flamenco, como si participara en una justa poética, utiliza el adjetivo «llagado» para improvisar un chiste que deleita a las supuestas damas, quienes solo quieren robarle lo poco que posee. Dice Antón:
¿Llagado? Deje. Escuche aqueste cuento:
En ciertas cañas que hubo en esta villa, sacó un galán pintada una esportilla en la adarga, y la letra decía: Gado, y todo junto: Es-por-ti-lla-ga-do. Mas cierta dama que lo vio, replica: «Aquella ¿es esportilla o esportica? porque si es esportica y Gado el mote, quedará el cifrador de bote en bote» ${ }^{3}$.

La prostituta, el blanco del chiste, señala que la salida de Antón ha tenido gracia y procede, sin escrúpulo alguno, a burlar al desastrado flamenco. Este chiste viene como anillo al dedo para entender los vínculos entre la ofensa, el insulto y la comicidad. La dama del chiste ofende a su caballero cuando pone en tela de juicio su capacidad intelectual, sugiriendo que el ingenio del caballero, al contrario del de ella, le ha sido insuficiente para darse cuenta de que un sencillo cambio de sufijo diminutivo («-illa» a "-ica» en el sustantivo "espuerta») modificaría de manera embarazosa el significado de la empresa amorosa de la adarga. En otras palabras, la dama indica que el caballero es un menguado, se burla de su dolor y prueba su propia superioridad intelectual, haciendo así reír al público del entremés. El contexto mismo del juego de cañas es propicio para ilustrar la relación entre ofensa, insulto y comicidad. Explican Evangelina Rodríguez Cuadros y Antonio Tordera, en su edición de La casa holgona, que «las escaramuzas de adargas eran una pervivencia de la caballería medieval. La adarga era un escudo de cuero de forma ovalada $»^{4}$. En este tipo de torneo, los caballeros se daban botes con cañas a modo de lanzas. Poco se esperaba el caballero, sin embargo, que una dama fuera a darle un bote

2 Calderón, La casa holgona, 1989, p. 100.

3 Calderón, La casa holgona, 1989, p. 100.

4 Calderón, La casa holgona, 1982, p. 109. 
con la lanza de su ingenio. Se trata de un bote intelectual que hiere su dignidad y que lo ridiculiza, produciendo así la risa. La punta de las cañas, punta roma que no mata pero que sí causa molestia, funciona como metáfora de la agudeza con la que la dama vence al caballero en este juego de cañas del ingenio. La ofensa, el insulto y la comicidad coinciden, así, en llevar una carga de agresividad, la cual encierra una actitud de superioridad por parte del que insulta y ríe. En este artículo exploraremos la manera en que un conocido chistecillo popular se incorpora en La casa holgona. Investigaremos, además, cómo un procedimiento emblemático permite matizar y enriquecer el significado de la facecia original para insultar a una de las damas y producir la risa.

En el Tesoro de la lengua castellana, Sebastián de Covarrubias no incluye el sustantivo "ofensa", aunque sí define el verbo "ofender», explicando que significa «hacer daño a otro. Lat. offendere, ofendido: el que ha recibido la ofensa» ${ }^{5}$. El Diccionario de autoridades corrobora esta definición: «daño, injuria o agravio que se hace a otro de palabra u obra» ${ }^{6}$. Para Covarrubias, el insulto constituye un «hecho malo, atrevido y escandaloso» ${ }^{7}$ y, según el Diccionario de autoridades, es un «acometimiento violento o improvisto» ${ }^{8}$. El Diccionario de la lengua española de la Real Academia vincula ofensa e insulto al indicar que "ofender» es la acción de «humillar o herir el amor propio o la dignidad de alguien, o ponerlo en evidencia con palabras o con hechos» ${ }^{9}$ e $« i n s u l-$ tar» consiste en "ofender a alguien provocándolo e irritándolo con palabras o acciones» ${ }^{10}$. Como lo señala Covarrubias, la ofensa le hace daño a otro y el insulto también puede hacerlo, puesto que es «acometimiento o asalto repentino y violento», según una acepción desusada que aparece en el Diccionario de la Real Academia. De hecho, el elemento de violencia está presente en la etimología misma del vocablo «insulto», el cual proviene del latín «insultus» y de su verbo «insultare», que a su vez es un compuesto de «sultare» y del prefijo «in»; es decir, significa «saltar contra alguien o algo». El insulto podría, entonces, con-

5 Cov., p. 1321.

6 Aut, p. 20.

7 Cov., p. 1103.

8 Aut, p. 287.

${ }^{9}$ DRAE, p. 971.

10 DRAE, p. 779. 
siderarse una herramienta de la ofensa que tiene la capacidad para atacar y herir de manera violenta o imprevista al insultado. Constituye un arma, ofensiva o defensiva, con la que se puede acometer contra la honra, la apariencia fisica, la etnicidad o muchos otros aspectos del blanco que se encuentra en su mira. En el chistecillo de la esportilla, la dama ataca y ofende al caballero con un insulto cómico que arremete contra su inteligencia y ridiculiza sus pretensiones amorosas.

La ofensa, el insulto, y la comicidad comparten la agresión, elemento que, según algunas teorías, es clave para la producción de la risa. Las ideas áureas sobre la comicidad derivaban de teorías aristotélico-ciceronianas, según las cuales el sentimiento de superioridad, derivado de la fealdad o torpeza del otro (turpitudo et deformitas), es la fuente primordial de la risa. Resume esta teoría Alonso López Pinciano:

son muchos... los motivos y muchos los lugares (que causan la risa), porque la risa está fundada en un no sé qué de torpe y feo, de lo cual hay en el mundo más que otra cosa alguna. Sea, pues, el fundamento principal que la risa tiene su asiento en fealdad y torpeza ${ }^{11}$.

Y hace eco de esta idea Francisco Cascales:

Y Aristóteles dice «Ridiculum est peccatum quoddam ex turpitudine sine dolore». De aquí que la materia cómica hace mover a risa y que la risa es la burla sin dolor de alguna cosa torpe y fea ${ }^{12}$.

Parten ambos tratadistas de la idea de que el objeto de la risa es torpe o feo, y al no serlo yo, me siento superior a él. Coincide esta actitud con la de la ofensa y el insulto: el ofensor se siente o, cuando menos, pretende sentirse superior al ofendido. En el contexto de una obra dramática cómica, la risa del público puede ser el resultado de una ofensa o insulto que hiere y ridiculiza a un personaje. Claro, podemos identificarnos con el personaje insultado y no reírnos al sentirnos ofendidos, pero, momentáneamente, podemos suspender este sentimiento para así poder reír con el resto del público, ya que la risa

${ }^{11}$ López Pinciano, Philosophia antigua poetica, p. 33.

12 Cascales, Tablas poéticas, p. 221. 
es un fenómeno social. El teatro puede convertir, entonces, la violencia de la ofensa y del insulto en un recurso de la comicidad, como también convierte dolorosos golpes y porrazos en mecanismos productores de la risa.

La insistencia en la fealdad y la torpeza es clave en el funcionamiento del género entremesil. Señalan Rodríguez Cuadros y Tordera que, desde el punto de vista de la comicidad, «la obra dramática corta queda definida básicamente por dos conceptos sobre los que los teóricos vuelven con insistencia» ${ }^{13}$. Uno de estos conceptos es la «clara relación de proximidad (no necesariamente dependencia) respecto a la comedia» ${ }^{14}$. El otro concepto, que «lo cómico en el entremés reside en la burla y en el concepto clásico de turpitudo et deformitas» ${ }^{15}$, coincide con las teorías áureas de la comicidad.

Uno de los objetivos del género entremesil es hacer reír y, con frecuencia, una serie de situaciones jocosas forman, artificiosamente, su estructura. Sabemos, además, que la humillación y la agresión son elementos claves en la estética y la estructura entremesiles. Afirma Vicente Pérez de León que «La evolución del género del teatro breve culminó en el siglo XVII con una sucesión de diálogos interrumpidos con bromas de personajes que se agreden, insultan, humillan y aparentan divertirse con el resultado de las burlas» ${ }^{16}$. La ofensa entremesil se nutre de la cultura popular carnavalesca pero también de prácticas literarias bien establecidas en la poesía burlesca, el teatro cómico y la sátira. La ofensa en La casa holgona no es excepción a esta regla y bebe de estas tradiciones, las cuales estiliza y refina Calderón con su propia agudeza e ingenio, a medida que crea y recrea elementos populares de manera novedosa.

El chiste de la empresa de la esportilla es uno de los elementos cómicos populares que utiliza y modifica Calderón en la composición de La casa holgona. Contrario a la propuesta de Rodríguez Cuadros y Tordera, quienes sugieren que «más que un cuento tradicional, parece invención grotesca de Calderón, recurso muy típico en él $\gg^{17}$, podemos

13 Calderón, La casa holgona, 1982, p. 17.

14 Calderón, La casa holgona, 1982, p. 17.

15 Calderón, La casa holgona, 1982, p. 17.

16 Pérez, 2004, p. 14.

17 Calderón, La casa holgona, 1982, p. 109. 
constatar que se trata de un chistecillo tradicional, que recogen, con anterioridad a la composición del entremés, Melchor de Santa Cruz en Floresta española [1574] y Francisco Agustín Tárrega en Discurso o recopilación de las necedades más ordinarias en que solemos caer hablando [1592]. También hace mención de él, posteriormente, Gracián en su Agudeza, tanto en la versión inicial de 1642, como en la definitiva de1648. Un examen de estas tres variantes del chiste de la esportilla nos permite entender cómo lo incorpora Calderón en La casa holgona. En Floresta española, aparece así: "Uno traía en una capa bordadas unas esportillas, y cabe cada una esportilla estas letras: "gado", que quiere decir "es por ti llagado". Don Alonso de Aguilar se allegó a él, y le dijo: - Señor, si como es esportilla, fuera esportica, ¿qué diría?» ${ }^{18}$. Tárrega lo presenta de esta manera: "Otro, sobre una esportilla y un corazón puso por mote "Gado", y preguntándole que significaba declaró su jerigonza que decía: "Es por ti llagado”.Y como le replicaren: “¿Si como v.m. lee esportilla leyese otro esportica, que es muy contingente, qué tal quedaría ese malaventurado corazón?”»19. Tárrega reduce las múltiples esportillas a una, añade un corazón y reemplaza a Don Alonso de Aguilar por un personaje anónimo. La adición de otro elemento visual a la empresa no deja duda alguna de que es el corazón el que queda cubierto de excrementos. Gracián no reproduce el cuento, sino que cambia el reparto de personajes cuando en la sección de empresas amorosas del Discurso LVII, «De otras especies de agudeza fingida», menciona "el corazón y la esportilla del Condestable, graciosamente comentado del Gran Capitán $»^{20}$. Añade una explicación en la que señala que este tipo de empresa de «las propias de España», cuyo artificio consiste «no en la semejanza de la pintura con el intento que se pretende, sino en que el nombre de la cosa pintada, o solo, o ayudado de otra palabra, exprima y diga lo que se pretende, de modo que la pintura en estos no representa tanto cuanto substituye por su voz y dicción» ${ }^{21}$. Acordamos con Maxime Chevalier que, dado el cambio de personajes en las varias versiones escritas del chistecillo, «se puede

18 Santa Cruz, Floresta española, p. 46.

19 Tárrega, Discurso o recopilación de las necedades más ordinarias en que solemos caer hablando, p. 425; también se cita en Madroñal, 2006, p. 171.

${ }^{20}$ Gracián, Agudeza y arte de ingenio, p. 215.

21 Gracián, Agudeza y arte de ingenio, p. 215. 
defender la hipótesis de que se trata de un chiste común, que atribuían los que lo relataban a cualquier personaje, más o menos famoso en los anales de España»22, y, añadimos, a cualquier personaje que no fuera famoso, como lo es el caso de los habitantes de La casa holgona.

En La casa holgona, el chistecillo de la esportilla se convierte en un complejo recurso dramático. La estructura del funcionamiento del chiste en este entremés consta de dos niveles: el primero consiste en el efecto cómico que puede funcionar fuera del contexto dramático y sin referencia a este; el segundo, por lo contrario, surte efecto solo cuando se considera en relación con la acción entremesil. Este procedimiento doble permite que el chiste sufra una metamorfosis y asuma, al menos, dos niveles de significado.

El primer nivel, el del chistecillo en sí, lo hemos explorado parcialmente en la introducción. Ahora, procederemos a explicar en mayor detalle cómo manipula Calderón la facecia de la esportilla. No se contenta el autor con copiar el chiste, sino que, como lo hace Gracián, cambia sus personajes: ahora son una dama y el caballero que la corteja. Como en las variantes de Floresta española y Discurso y recopilación, incluye el mote, "Gado», y solo una esportilla, como en los casos de Tárrega y Gracián. Menciona, además, que el caballero quedará «de bote en bote» ${ }^{23}$ y, como Santa Cruz, deja por sobrentendido el corazón del grabado de la empresa, lo que podría indicar que los detalles del chistecillo eran bien conocidos en la época. A pesar de su ausencia, la referencia al corazón es clave para entender el juego cómico del chiste en La casa holgona, como veremos más adelante. En la versión calderoniana una dama insulta la capacidad intelectual de un caballero que lleva una empresa amorosa en su adarga para un juego de cañas. La lectura que hace la dama de la combinación de imagen y letra cambia el significado que le quería dar el caballero, al cambiar el referente amoroso por uno escatológico: con un sencillo juego lingüístico, la dama toma el lema, «es-por-ti-lla-ga-do», cambia el sufijo diminutivo, remplazando así el participio pasado («llagado») por otro («cagado»). El resultado es un nuevo lema con un nuevo significado. Estas dos lecturas de la empresa se relacionan a nivel semántico, puesto que en ambos casos el caballero sale mal librado. Si bien es cierto, la referencia

22 Chevalier, 1976, p. 353.

23 Calderón, La casa holgona, 1989, p. 100. 
escatológica lo degrada más que la amorosa: el paso del marco de referencia de las emociones más nobles a aquel de las funciones fisiológicas elimina la dignidad y decoro que encierra un corazón «llagado» de amor. Se da aquí un ejemplo de la torpeza y fealdad aristotélicas que, según el Pinciano y Cascales, ridiculizan a un personaje, haciendo que el público lo considere inferior y rompa a carcajadas o al menos sonría. Es decir, el sentimiento de superioridad que acompaña el ataque contra el caballero fundamenta la comicidad de este juego de palabras. Hay, sin embargo, otro elemento que produce la risa: la aparición repentina del nuevo marco fisiológico de referencia y su contraste con el marco de las emociones. Este mecanismo de la comicidad coincide con las teorías de raigambre kantiana, las cuales proponen que la risa resulta de una incongruencia inesperada entre marcos de referencia dispares. Según estas teorías de incongruencia, la aparición súbita de un elemento que no se relaciona, bajo condiciones normales, con el original es el estímulo que desencadena la risa. Entra en juego, además, el aspecto carnavalesco bakhtiniano, puesto que se baja de la esfera superior de las emociones a la esfera inferior de las funciones corporales.

Los siguientes interrogantes resultan de suma utilidad para entender el funcionamiento del chiste de la esportilla como ofensa o insulto $^{24}$. Primero, vale preguntar quién lo dice: lo dice una dama. Segundo, consideremos a quién se dirige: a un caballero torneante, aunque no parece decírselo directamente a él, puesto que asumimos que él está en el campo para empezar el juego y ella entre el público. Quizás cuenta ella su versión a sus amigas que la acompañan al juego de cañas. Tercero, pensemos en qué circunstancias se echa el chiste: precisamente durante un juego de cañas en que el caballero comunica, por medio de la empresa grabada en su adarga, los sentimientos que tiene por su dama. Cuarto, señalemos el objetivo de este insulto: la dama lo formula para ridiculizar las pretensiones amorosas del caballero, implicando que es un menguado que no se dio cuenta de las consecuencias semánticas de un sencillo cambio morfológico. Si la interpretación de la dama es correcta, entonces el caballero perderá el juego o, más bien, los juegos: el de cañas y el lingüístico.

${ }^{24}$ Para comprender y analizar el funcionamiento de los insultos nos fue de gran utilidad el estudio de Conley, 2010. 
Aquel, porque su contendiente masculino le dará botes repetidamente con su caña; es decir, perderá el juego «de bote en bote», con cada golpe que le den. De manera más degradante, la dama arremete contra el caballero con las agudas lanzas de su ingenio. Sabemos que la expresión, "estar de bote en bote», ahora y en el siglo XVII, se aplica a un establecimiento, como lo podría ser un bar o taberna, que está abarrotado o lleno. De manera sorprendente e inesperada, la dama remplaza el referente normal de la expresión, un lugar, por uno nuevo, un órgano del cuerpo humano: el corazón del caballero está «de bote en bote», es decir, lleno. Si la lectura preferida es «es-por-ti-caga-do», queda entonces claro de qué está lleno el corazón del burlado caballero. La comicidad aquí radica en un insulto que la dama lanza al caballero, diciéndole que se halla lleno de excrementos, es decir, que no se le puede creer lo que dice sobre su pasión amorosa. Opera aquí el principio de la superioridad en la producción de la risa y, también, el mecanismo de la incongruencia, puesto que se sorprende al público con cambios de marco de referencia, que intensifican el impacto del chiste: de un juego de cañas que se pierde con botes de cañas se pasa a un juego intelectual que se pierde con botes de ingenio; del corazón se pasa al hígado y de una referencia a un establecimiento abarrotado se pasa a una referencia a funciones fisiológicas. Así funciona el primer nivel del chiste, la comicidad que puede tener efecto fuera del contexto dramático.

El segundo nivel se encuentra en la acción misma del entremés, en el momento en que Antón cuenta a las damas el chiste del juego de cañas. Nos preguntamos para qué se presenta este chiste en el entremés, ya que parece estar fuera de lugar. Antón piensa en este chiste y lo echa después de que una de las prostitutas que lo están estafando, la Dama 3ra, utiliza la palabra «llagado». En las justas poéticas, que frecuentaba Calderón, el reto consistía con frecuencia en que, a partir de una palabra o idea, los competidores compusieran poemas, que a veces tomaban la forma de emblemas o empresas: Antón hace lo mismo a partir del adjetivo "llagado». El chiste que resulta es un insulto contra la Dama 3ra. Veamos si este es el caso. Haremos aquí las mismas preguntas que hicimos para analizar el insulto que contiene el primer nivel del chistecillo. Primero, ¿quién cuenta el chiste? Antón. Segundo, ¿a quién se lo dice? Directamente a una dama que finge sentirse ofendida por el tratamiento que le brinda. Tercero, ¿en qué cir- 
cunstancias? En el contexto de la burla y estafa que le hacen las damas de la casa holgona al no prestarle ningún servicio y, para colmo de males, robarle la capa, el sombrero, el pañuelo y ocho reales. Además, también está en el contexto específico de la respuesta que Antón da a la queja de Dama 3ra. Esta, como ya lo hemos señalado, se queja de que Antón le ha herido el corazón, el bazo y el hígado. Cuarto, ¿para qué echa este chiste Antón? Lo hace para informarle a la dama que no cree nada de lo que ella dice y que, además, se ha dado cuenta de que ella, y sus compinches, son unas estafadoras, quienes, dentro de los parámetros de su profesión, no prestan el servicio que ofrecen. Es decir, las ofende e insulta con un chiste, con un alfilerazo del ingenio, como lo hiciera contra el caballero, la dama del chiste con las lanzas de su ingenio.

El papel que desempeña la Dama 3ra como blanco del ataque es clave para entender el funcionamiento del chistecillo de la esportilla en el entremés. La dama dice sentirse ofendida por Antón: «el corazón me deja lastimado, / el bazo herido, el hígado llagado» ${ }^{25}$. El capigorrón escucha esta declaración de la Dama 3ra y se inspira en el adjetivo "llagado" para echar el chiste de la esportilla, pero hay que tener en cuenta que en el chiste el órgano llagado es el corazón, mientras que el órgano llagado de la Dama 3ra es el hígado. Según la dama, su corazón también está herido, pero prefiere modificar el sustantivo con el adjetivo "lastimado», a la vez que escoge el adjetivo «llagado» para modificar al sustantivo "hígado», elección de la que se agarra Antón para lanzar su dardo cómico. En el chiste del juego de cañas, el caballero se queja, por medio de su empresa amorosa, de que su dama le ha llagado el corazón. La dama, como hemos visto, no le cree y le dice que no está llagado de amor sino cagado o lleno de excrementos. En cierto sentido, el caballero desempeña un papel equivalente al de la Dama 3ra. Esta, a manera de caballero torneante de la casa holgona, le dice a Antón, con falsedad, que le ha dejado el hígado llagado; este le responde que no está llagado sino cagado. Es decir, le indica que el órgano no está limpio y que, por lo tanto, no funciona bien. El contraste entre el corazón llagado del caballero de las cañas y el hígado llagado de la Dama 3ra, en sí, tiene un efecto cómico, ya que

25 Calderón, La casa holgona, 1989, p. 100. 
contrasta la relación del corazón con funciones amorosas y la del hígado con funciones fisiológicas.

Podríamos decir, entonces, que la risa resulta aquí de un cambio de marco de referencia y de un sentimiento de superioridad, que surge de la capacidad de Antón para tomar lo que dice la dama y volverlo en contra de ella. Si bien esta interpretación es cierta, este juego va más allá y elabora con mayor sutileza el simbolismo de los órganos. Para empezar, el hígado es un órgano rico en significados. En su queja, la Dama 3ra se refiere a tres de los cuatro humores que conformaban el organismo según la teoría médica que formulara Hipócrates (460 a. C.-377 a. C.) y recogiera Galeno (130-216): el humor correspondiente al corazón es la sangre; al bazo, la bilis negra; y al hígado, la bilis ama-rilla. Sugiere esta selección de órganos heridos un desequilibrio en los temperamentos correspondientes: el sanguíneo, el melancólico y el colérico respectivamente. El hígado llagado, al que se refiere Antón, se relaciona entonces con una enfermedad del temperamento colérico, pero además se relaciona con la falta de escrúpulos, que es lo que demuestra la Dama 3ra al querer engañar a Antón. De hecho, el hígado se vincula con la concupiscencia, según las teorías clásicas que llegan a los Siglos de Oro, como indica Huarte de San Juan: «el hígado (donde reside la facultad concupiscible)...» ${ }^{26}$. Sabemos que la concupiscencia tiene que ver con el deseo de bienes materiales y el apetito de deseos sexuales. Un hígado llagado, es decir enfermo, implicaría un exceso desordenado de tales deseos y apetitos, una falta de escrúpulos para obtenerlos. Antón insinúa que el hígado de la engañosa dama no funciona bien, es decir, subraya los excesos sexuales de su profesión e indica que, aún dentro del marco ético de su profesión, ella no cumple con sus deberes, puesto que nunca se huelga con él y lo único que hace, junto con sus compinches, es engañarlo para robarle los pocos bienes que posee. Como la dama del juego de cañas que le insinúa al caballero que es más lista que él, Antón le dice a la Dama 3ra que, aunque ella lo está burlando, no es tan tonto como parece. Corre Antón el peligro de que su insulto se vierta sobre él mismo, pues también está sumido en los excrementos metafóricos del abuso al cual lo someten las habitantes de la casa holgona.

${ }^{26}$ Huarte de San Juan, Examen de ingenio para las ciencias, p. 582. 
El juego con el chistecillo tradicional de la esportilla es un ejemplo del ingenio, tan típico del Barroco. El dramaturgo utiliza un recurso emblemático (una empresa) y lo modifica, siguiendo el procedimiento emblemático más ortodoxo. Tal proceso, como lo señala Daniel Russell en The Emblem and the Device in France, busca fragmentar sistemas de significado de la Edad Media o de obras alegóricas conocidas para combinar los elementos fragmentados y crear así unidades significantes nuevas e inesperadas ${ }^{27}$. Por ejemplo, los emblemistas toman la tradicional imagen del olmo y la vid, cambian uno o ambos motivos (muro por olmo, yedra por vid) para crear así nuevos significados. Este mecanismo emblemático se caracteriza, en el mejor de los casos, por la dificultad y el reto a la inteligencia y a la imaginación. El autor de La casa holgona se enfrenta a este reto modificando la imagen emblemática que aparece en el chistecillo de la esportilla. Como hemos visto, el chiste contiene una empresa (combinación de imagen con un lema que resultaba en un enigma), que con frecuencia adornaba las adargas de los contendientes en los juegos de cañas y transmitía un mensaje personal. El dramaturgo reproduce el chistecillo en su forma canónica, conserva inicialmente la imagen de la empresa del original, pero, con prontitud y a la manera de los emblemistas, modifica uno de sus elementos: elimina el corazón y lo remplaza con el hígado. Las connotaciones del hígado, tan diferentes de las del corazón, transforman el significado de la empresa amorosa y la convierten en una empresa de bilis y temperamento colérico. La composición emblemática del chistecillo sirve para burlarse de un amoroso caballero, mientras que la empresa que crea Antón, al manipular la composición original, ataca a la engañosa Dama 3ra. Tenemos aquí un ejemplo del procedimiento emblemático: se parte de una combinación tradicional de motivos, que se modifica, para así crear un nuevo significado o significados. Calderón va un paso más allá del juego lingüístico del chistecillo, lo embebe en una acción entremesil y lo convierte así en un eficaz recurso dramático cómico.

En suma, a partir del funcionamiento del chiste de la esportilla en La casa holgona, podemos llegar a varias conclusiones sobre la relación entre la comicidad y la ofensa. Ambas categorías comparten elementos como la agresividad y la superioridad, elementos que les permiten

27 Russell, 1985, p. 64. 
compaginarse para desempeñar un papel clave en la producción de la comicidad entremesil. En el caso del chiste de la esportilla, tenemos además de un cambio de marco de referencia repentino: de las emociones pasamos a las funciones fisiológicas, lo que encaja con el paso de las funciones superiores a las inferiores de las imágenes carnavalescas bakhtinianas. No necesariamente se produce una risa de carcajada, pero, como mínimo, se desprendería una sonrisa de complicidad entre el público y, en este caso, Antón. Calderón demuestra un claro conocimiento del mecanismo operante en la literatura emblemática (emblemas, empresas, jeroglíficos) y lo utiliza como punto de partida para elaborar una situación dramática, que, al hacer referencia a elementos escatológicos, le da vuelta de tuerca a una empresa amorosa y la embebe de manera orgánica dentro de la trama de La casa holgona. La elección de una empresa para crear una situación cómica es acertada, puesto que las composiciones emblemáticas constituyen un producto cultural, cuyo mecanismo conocía bien el público, ya que aparecían en el teatro, en sermones, en entradas reales y en fiestas públicas. Igualmente familiarizado estaría el público con el funcionamiento de chistes como el de la esportilla, que se basan en la superioridad y la incongruencia. Esta familiaridad con los mecanismos emblemático y cómico permitiría que el público siguiera con facilidad el juego intelectual a que se somete el chiste de la esportilla. El entretejimiento de un chiste popular con un elemento emblemático demuestra, una vez más, el poder del ingenio barroco y constituye un ejemplo de la riqueza y complejidad de los procedimientos cómicos del género entremesil. 


\section{BibLIOGRAFÍA}

Cascales, F., Tablas poéticas, ed. B. Francaforte, Madrid, Espasa Calpe, 1975. Calderón de la Barca, P., La casa holgona, en Teatro cómico breve, ed. M. ${ }^{a}$ L. Lobato, Kassel, Reichenberger, 1989.

- La casa holgona, en Entremeses, jácaras y mojigangas, ed. E. Rodríguez Cuadros y A. Tordera, Madrid, Castalia, 1982.

Chevalier, M., «Gracián y la tradición oral», Hispanic Review, 44, núm. 4, 1976, pp. 333-356.

Conley, T., Toward a Rhetoric of Insult, Chicago / London, The University of Chicago Press, 2010.

Covarrubias, S., Tesoro de la lengua castellana o española, ed. I. Arellano y R. Zafra, Madrid / Frankfurt, Iberoameriana / Vervuert, 2006.

Diccionario de autoridades, Madrid, Gredos, 1963, 3 vols.

Diccionario de la lengua española, Madrid, Espasa Calpe, 1984.

Gracián, B., Agudeza y arte de ingenio, ed. E. Correa Calderón, Madrid, Castalia, 2001, vol. 2.

Huarte de San Juan, J., Examen de ingenio para las ciencias, ed. G. Serés, Madrid, Cátedra, 1989.

López Pinciano, A., Philosophia antigua poetica, ed. A. Carballo Picazo, Madrid, CSIC, 1953, 3 vols.

MAdroñal, A., "Razones de la risa en el claustro (Los procedimientos humorísticos en los vejámenes de grado)», en Demócrito áureo: los códigos de la risa en el Siglo de Oro, ed. I. Arellano yV. Roncero, Sevilla, Renacimiento, 2006, pp. 143-178.

Pérez de León, V., «Sobre la realidad improvisada en el teatro breve del Siglo de Oro», Hispania, 87, núm. 1, 2004, pp. 13-21.

Russell, D., The Emblem and the Device in France, Lexington, French Forum Publishers, 1985.

Santa Cruz, M., Floresta española, ed. M. P. Cuartero y M. Chevalier, Barcelona, Crítica, 1997.

TÁrrega, F. A., Discurso o recopilación de las necedades más ordinarias en que solemos caer hablando, en De las Academias a la Enciclopedia, ed. E. Rodríguez Cuadros, Valencia, Edicions Alfonso el Magnànim, 1993. 